\title{
Responses to conspecific density in an arborescent bryozoan
}

\author{
Toby A. Gooley ${ }^{1}$, Dustin J. Marshall ${ }^{1,2}$, Keyne Monro ${ }^{1, *}$ \\ ${ }^{1}$ School of Biological Sciences and ${ }^{2}$ Centre for Marine Studies, The University of Queensland, St. Lucia, Queensland 4072 , \\ Australia
}

\begin{abstract}
Sessile colonial invertebrates that must tolerate environmental variation without the luxury of mobility may be expected to cope with such variation through phenotypic plasticity. While plastic responses to a range of biotic factors (e.g. predation) are increasingly documented, the details of responses to competition (mediated by the densities of conspecifics or heterospecifics vying for the same resources) remain unclear, despite a rich literature for terrestrial plants on which to draw. We examined phenotypic responses to conspecific density in a colonial invertebrate (the arborescent bryozoan, Bugula neritina) under field conditions. We found that colonies at higher densities were generally less fecund, lower in biomass and more elongate than those growing virtually alone. We also found such responses to vary only subtly with the life history stage of neighbours, with colonies exposed to higher densities of contemporary recruits achieving elongation via increased budding between bifurcation points and the elongation of individual zooids, while colonies exposed to established adults achieved elongation via increased budding only. These responses are broadly consistent with those of terrestrial plants competing for light and are probably due to the combined effects of resource limitation and altered flow in high density stands. Future studies are needed to disentangle these effects and the extent to which such responses to density in branching colonial invertebrates are a passive result of food limitation, or reflect active (and potentially adaptive) plasticity to other aspects of the local density environment.
\end{abstract}

KEY WORDS: Branching $\cdot$ Colony form $\cdot$ Density $\cdot$ Foraging behaviour $\cdot$ Intraspecific competition plasticity $\cdot$ Bryozoa

Resale or republication not permitted without written consent of the publisher

\section{INTRODUCTION}

Sessile marine invertebrates face the considerable challenge of being fixed to the substrate for much of their lifespan while inhabiting environments where conditions can vary on remarkably small spatial and temporal scales. Without the luxury of mobility, such organisms may often cope with environmental variation through phenotypic plasticity; that is, by expressing different phenotypes in response to different biotic or abiotic cues (Bradshaw 1965, Harvell \& Padilla 1990, Hughes 2005). Various cues are known to induce plastic responses in the sessile inhabitants of marine environments. Physical stresses, such as flow, are known to modify growth and morphology in both unitary and colonial (modular) organisms across a wide range of taxa (e.g. Okamura 1992, Marchinko 2003, Stewart \& Carpenter 2003). Predation, or cues that predict an increased threat of predation in the future, can induce predation-resistant phenotypes, as seen, for example, through the induction of spines in bryozoans (Harvell 1992), of 'bent' shell morphologies in barnacles (Lively 1986) and of thicker shells in mobile (but nonetheless sedentary) gastropods (Trussell 1996). Plastic responses to competition in sessile marine taxa are understood in less detail, however, despite the fact that competition for space-presumably mediated by local densities of conspecifics or heterospecifics vying for 
the same fixed resource - is widely believed to determine the structure of many benthic communities (Jackson 1977, Vermeij \& Sandin 2008).

To date, research on phenotypic responses to density in such systems has emphasised changes in overall growth and reproductive output, especially in encrusting bryozoans and ascidians (e.g. Sebens 1982, Buss 1990, Stocker \& Underwood 1991, Dias et al. 2008). As expected, individuals at lower densities with access to more space (and hence to more energy and nutrient sources like sunlight, suspended food particles or dissolved chemical compounds; Sebens 1982) often grow faster, larger and more fecund than crowded individuals. In other cases, however, this expectation is not met (Stocker \& Underwood 1991, Abdo et al. 2008), possibly because adverse effects of competition on performance are ameliorated by responses in other (e.g. morphological) traits. For example, barnacles at high conspecific densities may express a tall 'hummocked' morphology that improves access to suspended food particles (Bertness et al. 1998). Similarly, encrusting bryozoans that are encroached upon may start to produce stolons that slow the growth of adjacent competitors (Padilla et al. 1996), while spreading of the colonial test, aided by reductions in zooid size and density, may help colonial ascidians to pre-empt space from neighbours before actual contact is made (Marshall et al. 2006). These latter cases illustrate the potential flexibility afforded by modular construction, which may allow organisms that grow by iterating morphological subunits to serially adjust their phenotypes in response to local conditions (Hughes 2005). There is now a need to better understand phenotypic responses to density in other modular invertebrates, particularly those with arborescent growth for which there is abundant literature on terrestrial analogues on which to draw.

Plant responses to crowding, mediated directly by resource availability or by cues that predict future competition for resources, constitute some of the bestknown examples of growth-form variation in modular taxa and convincingly show how plasticity in various components of growth can enhance performance in heterogeneous environments (Schmitt \& Wulff 1993, Sultan \& Stearns 2005). In many non-clonal species, for example, shade produced by neighbours induces apical dominance and shoot elongation, which project resource-acquiring structures (leaves) upward into patches of higher light availability (the so-called shade-avoidance syndrome; Schmitt et al. 2003). Likewise, many clonal species 'forage' for patchily distributed resources in an environment by proliferating and/or elongating shoots or roots according to resource availability, a response that may help individuals to exploit more favourable patches and avoid or vacate those of lesser quality (Lovett Doust 1981, de Kroon \&
Hutchings 1995, Ye et al. 2006). Hence, growth form as a whole is considered an important life history trait in plants and is further expected to interact with a suite of others, such as growth, size at reproduction and fecundity (Sackville Hamilton et al. 1987, Fischer et al 2004). In systems where this is the case, responses to density may not only manifest in individual traits, whether vegetative or reproductive, but also involve shifts inallocation to these respective functions (Donohue \& Schmitt 1999, van Kleunen et al. 2005). Importantly, relatively little attention has been paid to applying this well-developed framework for understanding density effects on branching modular organisms to colonial marine invertebrates (Tanner 1997, Hughes 2005).

Here, we examined phenotypic responses to conspecific density in an arborescent bryozoan, Bugula neritina, whose larvae settle in aggregations (Raimondi \& Keough 1990) and whose erect growth form distinguishes it from most other (encrusting) taxa in the sessile invertebrate assemblages where it occurs. Thus, individuals may be more likely to interact competitively with other conspecifics than with heterospecifics lying prone beneath colony canopies (Silvertown 2004, Hart \& Marshall 2009). We manipulated the levels of density faced by individual settlers in the field by exposing them to no conspecifics, increased density of contemporary recruits or increased density of established adults (which were older and therefore larger than contemporaries). We examined several components of the response to each treatment: namely, the elongation of branches, the frequency of zooid budding between branch points and the elongation of individual zooids (all of which are essential components of growth form in this species), as well as colony size and fecundity. Using a multivariate approach to compare the phenotypes of $B$. neritina colonies across treatments, we found conspecific density to have complex effects that varied only subtly with the life history stage of neighbours.

\section{MATERIALS AND METHODS}

Study species and site. Bugula neritina is an arborescent bryozoan that occurs globally and is considered invasive in Australia, where our study was conducted (Hewitt et al. 2004). After settlement, colonies form as small stalks that grow and branch at distal tips via the asexual budding of paired zooids. Keough \& Chernoff (1987) found branching in $B$. neritina to be independent of colony size, often (but not always) with 4 zooid pairs per internode (i.e. regions between bifurcation points). Like all bryozoans, $B$. neritina is a sessile suspension-feeder, and occurs on hard substrates with other (primarily encrusting) organisms of this kind. 
Because such assemblages are typically limited by the availability of space on or directly above the substratum (Jackson 1977, Sebens 1982), competitive interactions within and among species intensify with crowding, which is therefore likely to mediate many aspects of colony phenotype (see Buss 1981 and Okamura 1984 for examples involving other Bugula species). All experimental work was conducted on floating pontoons at Scarborough Boat Harbour $\left(27^{\circ} 10.75^{\prime} \mathrm{S}\right.$, $153^{\circ}$ 06.3' E) in Moreton Bay, Brisbane, Queensland.

Expt 1: effects of density of contemporary recruits. To examine the effects of density of contemporary recruits, large mature colonies were transported from the field to the laboratory and held in light-proof aquaria of aerated seawater for $48 \mathrm{~h}$. They were then exposed to bright light to stimulate the release of larvae (Marshall \& Keough 2003), which were transferred via pipette to $90 \mathrm{~mm}$ diameter Petri dishes containing field-collected seawater to settle. To encourage settlement, dishes were pre-roughened and coated with natural biofilms that developed over several days' immersion at the field site. At this point, we established 2 treatments that differed with regard to conspecific density: a 'low conspecific density' treatment comprising 1 settler per dish (i.e. 1 focal settler with no contemporary recruits), and a 'high conspecific density' treatment comprising 8 settlers per dish (i.e. 1 focal settler plus 7 contemporary recruits). Due to the risk of high post-settlement mortality, dishes were initially inoculated with excess settlers that were randomly culled to the desired density $2 \mathrm{~d}$ after the experiment was deployed in the field. Each focal settler was circled with a pencil mark for subsequent identification.

Once settlers had completed metamorphosis, we transported them to the field (a 45 min journey) in insulated aquaria. There, we bolted 2 replicate dishes per treatment to the corners of $500 \times 500 \times 8 \mathrm{~mm}$ PVC backing panels (this arrangement ensured that dishes were spaced sufficiently apart to prevent unwanted interactions among replicates). To reduce the effects of light and sedimentation, panels were then suspended facedown from floating pontoons at $\sim 1 \mathrm{~m}$ below the water surface. We deployed 9 such panels in the first run of this experiment (Run 1) and 10 such panels in a second run (Run 2) a week later (all methods were consistent between runs). Dishes were checked and scraped weekly to remove new recruits whose settlement may have obscured our density manipulation. Because our goal was to examine the effects of conspecific density on morphology and reproduction, colonies were returned to the laboratory for measurement once the majority were reproductive ( $6 \mathrm{wk})$. On return, all focal colonies were digitally photographed. From these images, we measured the length of each internode, the number of zooids per internode and zooid length per internode (based on those zooids closest to each bifurcation point). All images were analysed using ImageJ (available at rsbweb.nih.gov/ $\mathrm{ij} /$ ). We further counted the number of ovicells per colony and the colony's dry weight, to the nearest milligram, once air-dried.

Expt 2: effects of density of established adults. To examine the effects of density of established adults, we grew Bugula neritina colonies on dishes that were deployed in the field on backing panels for $6 \mathrm{wk}$. These colonies were transported to the laboratory and larvae (spawned by freshly sampled mature colonies, as per the methods above) settled into their dishes to establish our 'high conspecific density' treatment (i.e. 1 focal settler plus 7 established adults). Larvae were also settled into empty pre-roughened and biofilmed dishes to establish our 'low conspecific density' treatment (i.e. 1 focal settler with no established adults). As in Expt 1, the risk of high post-settlement mortality led us to initially inoculate dishes in both treatments with excess settlers that were randomly culled to a single focal settler per dish $2 \mathrm{~d}$ after deployment in the field. Settlers were allowed to metamorphose before being transported to the field site and deployed on PVC backing panels. There were 6 panels (each holding 2 replicate dishes per treatment) deployed in a single run. A second run was deployed initially, but was lost due to an outbreak of predatory flatworms at our field site.

As in Expt 1, dishes were checked and scraped weekly to remove new recruits. Once most colonies were seen to be reproductive the experiment was concluded and all dishes were returned to the laboratory. There, focal colonies were processed as above to give measurements of internode length, zooid number per internode, zooid length per internode, colony fecundity and colony mass (the same 5 traits measured in Expt 1).

Data analyses. With regard to independent variables, data from Expt 1 were analysed in a general linear model that included conspecific density as a fixed categorical effect, run as a random categorical effect, and panel as a random categorical effect nested within run. Data from Expt 2 were analysed in a simpler model that included only conspecific density and panel as categorical effects. Full models were initially fitted to all interactions between categorical effects and reduced with regard to nonsignificant interactions as appropriate (Quinn \& Keough 2002).

With regard to dependent variables, we would have ideally analysed all 5 measured traits in the models as multivariate analyses of variance (MANOVA) without further manipulation, but could not do so due to their strong collinearity. We therefore used principal components analysis ( $\mathrm{PCA}$, on the correlation matrix) to distil these traits into a smaller number of principal 
components (PCs) and retained for analysis only those components with eigenvalues >1 (Jackson 1993). Note that these approaches should give broadly similar results (see Quinn \& Keough 2002, p. 457, on the relative advantages of each). Since PCA is robust to deviations from normality and homoscedasticity (Quinn \& Keough 2002), and residual plots and descriptive statistics showed no problems with either, untransformed data were analysed. We used Pillai's trace as the multivariate test statistic and univariate $F$ tests to show which PCs contributed to significant multivariate effects. All analyses were performed in Systat 12.0 .

\section{RESULTS}

\section{Expt 1: effects of density of contemporary recruits}

For Expt 1, a PCA of the measured traits yielded 2 PCs with eigenvalues $>1$. Together, these explained roughly $85 \%$ of total variance (note that for both experiments, the 3 lesser PCs explained relatively little variance and their exclusion from analyses did not cause any significant effects to be discarded; they are not dealt with further here). Given the trait loadings and SEs on each PC (Table 1), PC1 (explaining the most variance) was positively correlated with all original traits (i.e. more fecund colonies on this axis also had greater mass and longer internodes comprised of more and longer zooids). Such PCs with loadings of all the same sign are usually interpreted as measures of overall size that, once accounted for, permit examination of subsequent latent traits (Jolliffe 2002). PC2, which explained less but still had substantial variance, was negatively correlated with colony fecundity and mass, but was positively correlated with all other traits. On this axis, therefore, higher fecundity and mass coincided with a more compact growth form (i.e. shorter internodes consisting of fewer shorter zooids).

A MANOVA of these PCs detected a significant effect of the density of contemporary recruits on focal colonies, which univariate F-tests attributed to PC2 alone (Table 2). The presence of conspecifics thus had little effect on overall size (indicated by the similar scores of 'low conspecific density' and 'high conspecific density' colonies on PC1; Fig. 1). Rather, it altered patterns of allocation to the measured traits, with colonies investing more in elongation at the expense of fecundity and mass (indicated by colonies grown at high density having higher scores on PC2 than those grown at low density; Fig. 1). We also found PC1 to differ significantly between runs (Table 2), but this difference was independent of the density treatment effect and is not discussed further.
Table 1. Bugula neritina. The 2 largest principal components (PCs) of variation in the fecundity, mass and morphology at different densities of contemporary recruits. Shown for each $\mathrm{PC}$ is the trait loading (scaled to unit length), its SE and the percentage of total variation that the PC explains

\begin{tabular}{|lcc|}
\hline Trait & PC1 (SE) & PC2 (SE) \\
\hline Fecundity (ovicells) & $0.32(0.09)$ & $-0.72(0.07)$ \\
Mass (mg) & $0.44(0.06)$ & $-0.46(0.09)$ \\
Internode length (mm) & $0.52(0.04)$ & $0.24(0.07)$ \\
Zooids per internode & $0.47(0.05)$ & $0.30(0.10)$ \\
Zooid length (mm) & $0.46(0.05)$ & $0.36(0.09)$ \\
\% variance explained & 63.45 & 21.63 \\
\hline
\end{tabular}

Table 2. Bugula neritina. MANOVA (in bold) of the 2 largest principal components (PCs) of variation in the fecundity, mass and morphology at different densities of contemporary recruits. Univariate F-tests show which PCs contribute to significant multivariate effects. Note: reduced model after removal of non-significant interaction terms

\begin{tabular}{|lcccr|}
\hline Source of variation & $\mathrm{df}$ & Pillai trace & $F$ & \multicolumn{1}{c|}{$\mathrm{p}$} \\
\hline Conspecific density & $\mathbf{2 , 3 8}$ & $\mathbf{0 . 2 1}$ & $\mathbf{5 . 1 0}$ & $\mathbf{0 . 0 1}$ \\
PC1 & 1,39 & & 0.91 & 0.35 \\
PC2 & 1,39 & & 8.92 & $<0.01$ \\
Run & $\mathbf{2 , 1 5}$ & $\mathbf{0 . 3 2}$ & $\mathbf{3 . 4 7}$ & $\mathbf{0 . 0 6}$ \\
PC1 & 1,16 & & 7.30 & 0.02 \\
PC2 & 1,16 & & 0.06 & 0.82 \\
Panel (run) & $\mathbf{3 2 , 7 8}$ & $\mathbf{0 . 7 7}$ & $\mathbf{1 . 5 2}$ & $\mathbf{0 . 0 7}$ \\
PC1 & 16,39 & & 1.65 & 0.10 \\
PC2 & 16,39 & & 1.38 & 0.20 \\
\hline
\end{tabular}

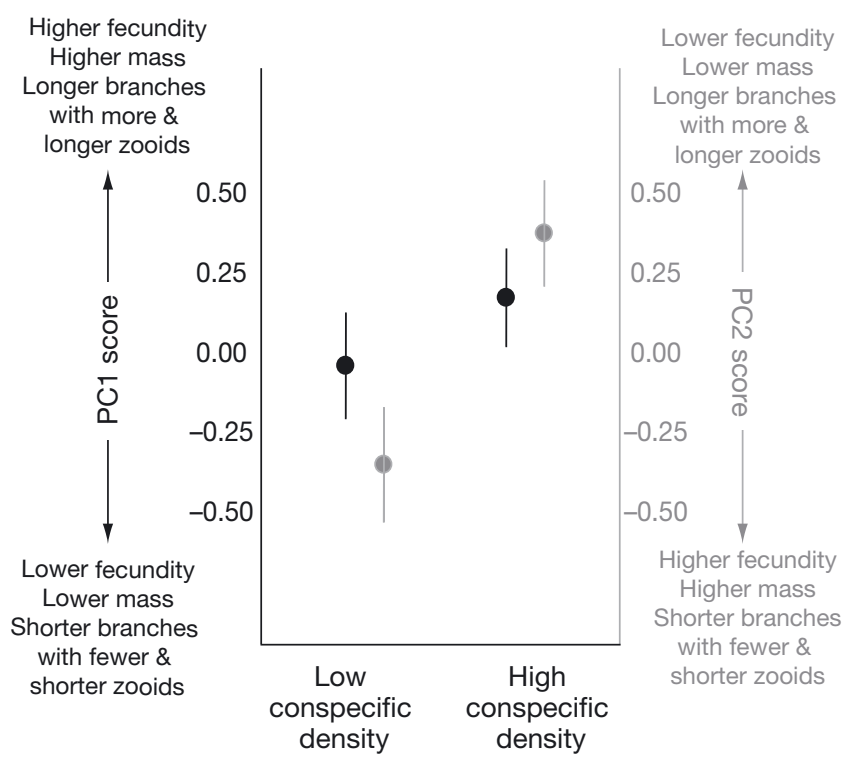

Fig. 1. Bugula neritina. The response of fecundity, mass and morphology to the surrounding density of contemporary recruits. Mean scores ( $\pm 1 \mathrm{SE}$ ) on PC1 and PC2 (see Table 1) are shown for colonies grown at low conspecific density and colonies grown at high conspecific density 


\section{Expt 2: effects of density of established adults}

For Expt 2, a PCA of the measured traits also yielded 2 PCs with eigenvalues $>1$. Together, these explained roughly $80 \%$ of total variance (Table 3 ) and were qualitatively similar in terms of trait loadings and amounts of variance explained to those obtained in Expt 1 (Table 1). We thus interpreted them as before, with PC1 describing overall size and PC2 describing differential allocation to the measured traits. Though PC2 was no longer associated with zooid length (whose trait loading was effectively zero, given its error), it was again negatively correlated with colony fecundity and mass, and positively correlated with internode length and the number of zooids per internode. Hence, as in Expt 1, higher fecundity and mass on PC2 coincided with an increasingly compact growth form (albeit one varying only with the degree of budding between bifurcations, not with zooid elongation).

Again, as in Expt 1, a MANOVA of these PCs detected a significant effect of conspecific densitythis time of established adults - on focal colonies, which univariate F-tests attributed to PC2 alone (Table 4). As before, the presence of conspecifics had little effect on overall size, but caused colonies to express a more elongate growth at the expense of fecundity and mass (again indicated by colonies grown at high density having higher scores on PC2 than those grown at low density; Fig. 2). No other effects were significant.

\section{DISCUSSION}

We found that the densities of surrounding conspecifics can have substantial effects on Bugula neritina colonies, with those growing at higher densities being generally less fecund, lower in biomass and more elongate in growth form than those growing virtually alone (i.e. with conspecifics at least $40 \mathrm{~cm}$ distant). We also found that such effects, and the details of how they manifest, vary only subtly with the life history stages of neighbours. In $B$. neritina colonies exposed to higher densities of contemporary recruits, for example, the elongation response was achieved by both increased budding between bifurcation points (producing more zooids per internode) and by the elongation of individual zooids. In colonies exposed to established adults, however, the elongation response was achieved by increased budding between bifurcations only, with no discernible input from zooid elongation.

These responses to conspecific density are likely to reflect intraspecific competition for resources (Buss 1981, Harvell et al. 1990). Density-dependent growth
Table 3. Bugula neritina. The 2 largest principal components (PCs) of variation in the fecundity, mass and morphology at different densities of established adults. Shown for each PC is the trait loading (scaled to unit length), its SE and the percentage of total variation that the PC explains

\begin{tabular}{|lcc|}
\hline Trait & PC1 (SE) & PC2 (SE) \\
\hline Fecundity (ovicells) & $0.33(0.15)$ & $-0.70(0.20)$ \\
Mass (mg) & $0.48(0.09)$ & $-0.30(0.18)$ \\
Internode length (mm) & $0.54(0.07)$ & $0.28(0.14)$ \\
Zooids per internode & $0.36(0.14)$ & $0.59(0.27)$ \\
Zooid length (mm) & $0.50(0.08)$ & $-0.03(0.26)$ \\
\% variance explained & 57.68 & 20.48 \\
\hline
\end{tabular}

Table 4. Bugula neritina. MANOVA (in bold) of the 2 largest principal components (PCs) of variation in the fecundity, mass and morphology at different densities of established adults. Univariate F-tests show which PCs contribute to significant multivariate effects. Note: reduced model after removal of non-significant interaction terms

\begin{tabular}{|lcccc|}
\hline Source of variation & df & Pillai trace & $F$ & $p$ \\
\hline Conspecific density & $\mathbf{2 , 1 6}$ & $\mathbf{0 . 3 3}$ & $\mathbf{3 . 9 8}$ & $\mathbf{0 . 0 4}$ \\
PC1 & 1,17 & & 0.33 & 0.58 \\
PC2 & 1,17 & & 6.94 & 0.02 \\
Panel & $\mathbf{1 0 , 3 2}$ & $\mathbf{0 . 6 0}$ & $\mathbf{1 . 4 5}$ & $\mathbf{0 . 2 0}$ \\
PC1 & 5,17 & & 2.51 & 0.07 \\
PC2 & 5,17 & & 0.64 & 0.68 \\
\hline
\end{tabular}

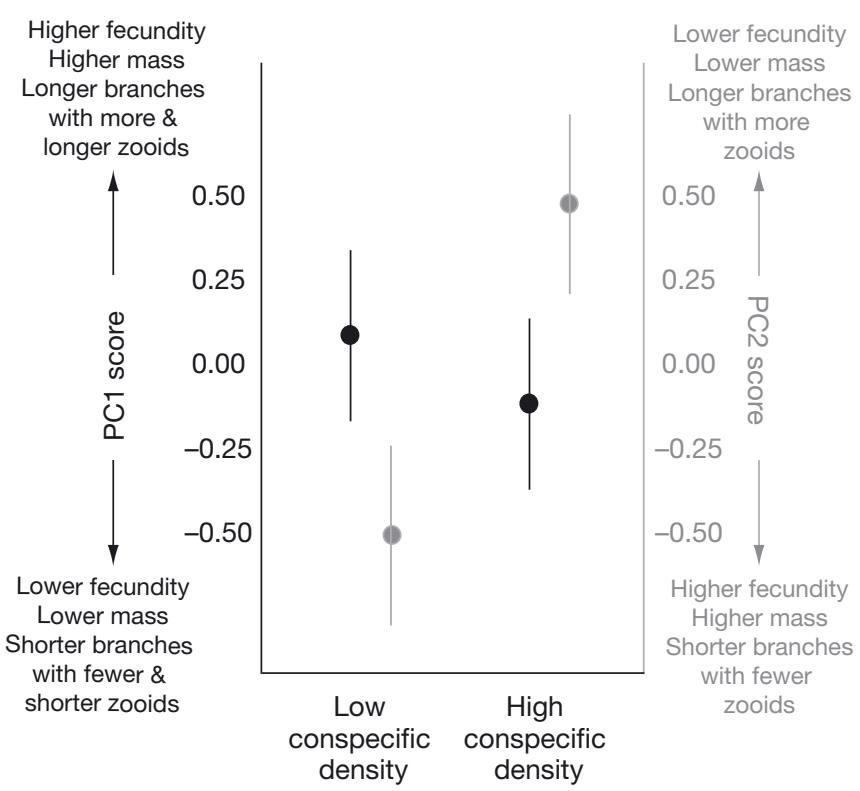

Fig. 2. Bugula neritina. The response of fecundity, mass and morphology to the surrounding density of established adults. Mean scores ( $\pm 1 \mathrm{SE}$ ) on PC1 and PC2 (see Table 3 ) are shown for colonies grown at low conspecific density and colonies grown at high conspecific density. Note that PC2 here (unlike

Expt 1; see Table 1) is not associated with zooid length 
and/or reproduction has previously been demonstrated in encrusting bryozoans (Harvell et al. 1990) and in the arborescent Bugula (Buss 1981, Allen et al. 2008), but the positive association between these performance measures that we consistently observed comes as more of a surprise, given that individuals might be expected to allocate more energy to one at the expense of the other. Support for this expectation comes from Harvell \& Grosberg's (1988) study of 2 phyletically distinct colonial invertebrates (the encrusting bryozoan, Membranipora membranacea, and the ascidian, Botryllus schlosseri), in which crowding by conspecifics triggered the onset of sexual reproduction while suppressing colony growth. Our result, however, is more consistent with Keough (1989b), who found growth and reproduction in Bugula neritina to also covary positively in response to fine-scale environmental variation - possibly because insufficient food early in life, or disease, may not only limit subsequent growth but lead to reproductive failure. Alternatively, this pattern might simply reflect the scaling of size and fecundity in modular taxa (Jackson et al. 1985, Hall \& Hughes 1996), or even the masking of expected trade-offs in resource allocation by relatively higher variation in acquisition among colonies (van Noordwijk \& de Jong 1986). However, our results extend those of previous studies by further linking variation in growth and reproduction to morphological variation. Responses to density were driven more by fecundity than any other measured trait (indicated by its consistently higher loading on $\mathrm{PC} 2$; see Tables 1 \& 3), but were also manifest in colony form. This then raises the possibility that changes in colony phenotype across density environments are not just passive effects of resource limitation, but also reflect growth-form plasticity that might actively enhance future access to resources.

The ecological literature abounds with descriptions of plant responses to density that can ameliorate, or even pre-empt, the adverse effects of resource limitation (see, for example, reviews by Donohue 2003, Schmitt et al. 2003 or de Kroon et al. 2005). Greater allocation to leaves or leaf surface area may maximise carbon gain in low light, thereby promoting shade tolerance (Valladares \& Niinemets 2008), while elongation responses to density that direct photosynthetic surfaces into more favourable parts of patchy light environments have been variously interpreted as part of a shade-avoidance syndrome (Schmitt et al. 2003) or 'foraging' for resources (Lovett Doust 1981, de Kroon \& Hutchings 1995). Such models have only occasionally been used to explain variation in the branching patterns of colonial invertebrates (Buss \& Blackstone 1991, Okamura 1992) or other sessile marine taxa such as seaweeds (ColladoVides 2002, Monro \& Poore 2005). We see the elongation responses of Bugula neritina colonies under com- petition as further evidence that ecological models developed for plants may apply well to analogous organisms in marine systems. In the same way that shoot elongation may help plants avoid or escape understorey shade and improve light interception (Donohue 2003), the elongation of internodes by increased budding (in Expts 1 and 2) and zooid elongation (in Expt 1) might possibly help $B$. neritina colonies to extend above neighbours and better intercept the flow of suspended food particles, or even release offspring into this flow for more effective dispersal.

What is currently unclear for any sessile marine organism, however, is the extent to which responses to density are mediated by resource limitation or by other aspects of the density environment, such as altered flow, which could possibly act as a cue for competitive conditions much like shifts in spectral quality as light filters through plant canopies (Schmitt \& Wulff 1993). Efforts to disentangle resource-mediated versus cuemediated effects in terrestrial systems - for example, by manipulating the spectral cue independently of density (Donohue \& Schmitt 1999) or other correlates of density such as light quantity (Griffith \& Sultan 2005) suggest that plants respond to them in different ways. Elongation is often induced by both cues for competition and immediate resource limitation (whether or not mediated by density), while growth and reproduction decline more with the latter (Donohue \& Schmitt 1999). This distinction shows that the ability to respond in a functionally appropriate way (i.e. with elongation) to cues for crowding before resources become limited may ultimately help individuals avoid competition for light (and the performance costs this incurs), and underpins the general view of this response as adaptive (Schmitt et al. 2003, Sultan \& Stearns 2005). Disentangling similar effects in marine systems is complicated by the fact that sessile suspension-feeders rely on flow for the delivery of suspended food particles. Neighbours may well compete directly for food as water flows through dense assemblages (Buss 1981, Buss \& Jackson 1981) but, as Okamura (1984) noted, competitive interactions in such systems may depend as much on flow as on food supply per se; that is, the disruption of flow as water moves through the branches of competitors may lower the flux of food particles to colonies downstream, signalling competition even when food is not yet limiting. Resolving this issue, and establishing the functional value of morphological responses to density, would ideally require independent manipulations of density, flow and food supply under natural conditions. To our knowledge, such studies are exceedingly rare (but see Padilla et al. 1996).

While principal components of different data sets are not directly comparable (though analyses based on correlation matrices, as we have done here, help in this re- 
spect; Jolliffe 2002), the similarity of our results across experiments suggests that responses to density in Bugula neritina depend only subtly on the life history stage of neighbours. In an earlier study at our field site, $B$. neritina settlers grew more poorly among established adults than among contemporary recruits at equivalent density (Allen et al. 2008), which was credited to stronger competition for resources from older larger colonies that have more 'mouths' to feed. Here, the joint response of growth, reproduction and morphology to density varied little in magnitude with the age of conspecifics, as did the relative contributions of individual traits (except for zooid elongation). It might be that competitive interactions among Bugula colonies vary with age in more complex ways if, for example, the larger colonies of established adults buffer new recruits from extreme flow, letting them feed at higher rates than those afforded less protection by contemporaries (Okamura 1984), or generate downward feeding-currents that carry food to underlying recruits (McKinney et al. 1986). Competitive interactions might then be most intense among contemporaries that filter water from similar heights above the substrate, perhaps explaining why zooid elongation (which increases the spacing of colony feeding structures and promotes more rapid elongation than increased budding alone) formed part of the response to density in Expt 1 only. However, without further insight into the functional significance of zooid elongation in arborescent taxa, this interpretation must remain speculative. Nor can we exclude the possibility that any differences between our experiments are due to factors (e.g. temporal variation in food supply) other than the life history stage of conspecifics. Indeed, Keough (1989a) found the presence of adults to have varying effects on the growth of $B$. neritina settlers within a single experiment, arguing that density interacts with other ecological factors in ways we do not yet understand.

In summary, we found that arborescent colonies of Bugula neritina showed integrated responsesnamely, reduced growth (as colony mass) and reproductive output, combined with internode elongation to the density of conspecific neighbours that varied little with regard to conspecific life history stage. Such responses, which probably reflect intraspecific competition for resources, could be due to the combined effects of resource limitation and altered flow in highdensity stands. While these effects cannot be disentangled here, we note that the elongation responses displayed by $B$. neritina are broadly consistent with those of terrestrial plants competing for light, and speculate that flow may act as a cue for competitive conditions in sessile invertebrate assemblages in a way analogous to shifts in spectral quality as light 'flows' through plant assemblages. We look forward to future studies that explore the extent to which such responses to density in branching colonial invertebrates are a passive outcome of food limitation, or reflect active (and potentially adaptive) plasticity to other aspects of the local density environment.

Acknowledgements. We thank members of the D. Marshall lab for help in the field, and Scarborough Marina for allowing us to use their facilities during the course of this study. We also thank several anonymous reviewers whose thoughtful comments greatly improved the manuscript.

\section{LITERATURE CITED}

Abdo DA, McDonald JI, Harvey ES, Fromont J, Kendrick GA (2008) Neighbour and environmental influences on the growth patterns of two temperate Haliclonid sponges. Mar Freshw Res 59:304-312

Allen R, Buckley Y, Marshall D (2008) Offspring size plasticity in response to intraspecific competition: an adaptive maternal effect across life-history stages. Am Nat 171: 225-237

Bertness MD, Gaines SD, Yeh SM (1998) Making mountains out of barnacles: the dynamics of acorn barnacle hummocking. Ecology 79:1382-1394

Bradshaw AD (1965) Evolutionary significance of phenotypic plasticity in plants. Adv Genet 13:115-155

Buss LW (1981) Group living, competition, and the evolution of cooperation in a sessile invertebrate. Science 213: 1012-1014

Buss LW (1990) Competition within and between encrusting clonal invertebrates. Trends Ecol Evol 5:352-356

Buss LW, Blackstone NW (1991) An experimental exploration of Waddington's epigenetic landscape. Phil Trans R Soc B Biol Sci 332:49-58

Buss LW, Jackson JBC (1981) Planktonic food availability and suspension-feeder abundance: evidence of in situ depletion. J Exp Mar Biol Ecol 49:151-161

Collado-Vides L (2002) Clonal architecture in marine macroalgae: ecological and evolutionary perspectives. Evol Ecol 15:531-545

de Kroon H, Hutchings MJ (1995) Morphological plasticity in clonal plants - the foraging concept reconsidered. J Ecol 83:143-152

de Kroon H, Huber H, Stuefer JF, van Groenendael JM (2005) A modular concept of phenotypic plasticity in plants. New Phytol 166:73-82

> Dias GM, Delboni CGM, Duarte LFL (2008) Effects of competition on sexual and clonal reproduction of a tunicate: the importance of competitor identity. Mar Ecol Prog Ser 362: $149-156$

Donohue K (2003) Setting the stage: phenotypic plasticity as habitat selection. Int J Plant Sci 164:S79-S92

Donohue K, Schmitt J (1999) The genetic architecture of plasticity to density in Impatiens capensis. Evolution 53: $1377-1386$

Fischer M, van Kleunen M, Schmid B (2004) Experimental life-history evolution: selection on growth form and its plasticity in a clonal plant. J Evol Biol 17:331-341

Griffith TM, Sultan SE (2005) Shade tolerance plasticity in response to neutral vs green shade cues in Polygonum species of contrasting ecological breadth. New Phytol 166:141-148

Hall VR, Hughes TP (1996) Reproductive strategies of modular organisms - comparative studies of reef-building corals. Ecology 77:950-963

Hart SP, Marshall DJ (2009) Spatial arrangement affects pop- 
ulation dynamics and competition independent of community composition. Ecology 90:1485-1491

Harvell CD (1992) Inducible defenses and allocation shifts in a marine bryozoan. Ecology 73:1567-1576

> Harvell CD, Grosberg RK (1988) The timing of sexual maturity in clonal animals. Ecology 69:1855-1864

$>$ Harvell CD, Padilla DK (1990) Inducible morphology, heterochrony and size hierarchies in a colonial invertebrate monoculture. Proc Natl Acad Sci USA 87:508-512

Harvell CD, Caswell H, Simpson P (1990) Density effects in a colonial monoculture: experimental studies with a marine bryozoan (Membranipora membranacea L.). Oecologia 82:227-237

> Hewitt C, Campbell M, Thresher R, Martin R and others (2004) Introduced and cryptogenic species in Port Phillip Bay, Victoria, Australia. Mar Biol 144:183-202

Hughes RN (2005) Lessons in modularity: the evolutionary ecology of colonial invertebrates. Sci Mar 69:S169-S179

Jackson JBC (1977) Competition on marine hard substrata: the adaptive significance of solitary and colonial strategies. Am Nat 111:743-767

> Jackson DA (1993) Stopping rules in principal components analysis: a comparison of heuristical and statistical approaches. Ecology 74:2204-2214

Jackson JBC, Buss LW, Cook RE (1985) Clonality: a preface. In: Jackson JBC, Buss LW, Cook RE (eds) Population biology and evolution of clonal organisms. Yale University Press, New Haven, p ix-xi

Jolliffe IT (2002) Principal component analysis. SpringerVerlag, New York

Keough MJ (1989a) Dispersal of the bryozoan Bugula neritina and effects of adults on newly metamorphosed juveniles. Mar Ecol Prog Ser 57:163-172

Keough MJ (1989b) Variation in growth rate and reproduction of the bryozoan Bugula neritina. Biol Bull (Woods Hole) 177:277-286

Keough MJ, Chernoff H (1987) Dispersal and population variation in the bryozoan Bugula neritina. Ecology 68:199-210

Lively CM (1986) Predator-induced shell dimorphism in the acorn barnacle Chthamalus anisopoma. Evolution 40: $232-242$

Lovett Doust L (1981) Population dynamics and local specialization in a clonal perennial (Ranunculus repens). I. The dynamics of ramets in contrasting habitats. J Ecol 69: 743-755

Marchinko KB (2003) Dramatic phenotypic plasticity in barnacle legs (Balanus glandula Darwin): magnitude, age-dependence, and speed of response. Evolution 57: 1281-1290

Marshall DJ, Keough MJ (2003) Variation in the dispersal potential of non-feeding invertebrate larvae: the desperate larva hypothesis and larval size. Mar Ecol Prog Ser 255:145-153

Marshall DJ, Cook CN, Emlet RB (2006) Offspring size effects mediate competitive interactions in a colonial marine invertebrate. Ecology 87:214-225

McKinney FK, Listokin MRA, Phifer CD (1986) Flow and polypide distribution in the cheilostome bryozoan Bugula and their inference in Archimedes. Lethaia 19:81-93

Monro K, Poore AGB (2005) Light quantity and quality induce shade-avoiding plasticity in a marine macroalga. J Evol Biol 18:426-435
Okamura B (1984) The effects of ambient flow velocity, colony size, and upstream colonies on the feeding success of Bryozoa. I. Bugula stolonifera Ryland, an arborescent species. J Exp Mar Biol Ecol 83:179-193

> Okamura B (1992) Microhabitat variation and patterns of colony growth and feeding in a marine bryozoan. Ecology 73:1502-1513

Padilla DK, Harvell CD, Marks J, Helmuth B (1996) Inducible aggression and intraspecific competition for space in a marine bryozoan, Membranipora membranacea. Limnol Oceanogr 41:505-512

Quinn GP, Keough MJ (2002) Experimental design and data analysis for biologists. Cambridge University Press, Cambridge

Raimondi PT, Keough MJ (1990) Behavioural variability in marine larvae. Austral Ecol 15:427-437

Sackville Hamilton NR, Schmid B, Harper JL (1987) Life-history concepts and the population biology of clonal organisms. Proc R Soc Lond B Biol Sci 232:35-57

> Schmitt J, Wulff RD (1993) Light spectral quality, phytochrome and plant competition. Trends Ecol Evol 8:47-51

Schmitt J, Stinchcombe JR, Heschel MS, Huber H (2003) The adaptive evolution of plasticity: phytochrome-mediated shade avoidance responses. Integr Comp Biol 43: 459-469

Sebens KP (1982) Competition for space: growth rate, reproductive output, and escape in size. Am Nat 120:189-197

Silvertown J (2004) Plant coexistence and the niche. Trends Ecol Evol 19:605-611

> Stewart HL, Carpenter RC (2003) The effects of morphology and water flow on photosynthesis of marine macroalgae. Ecology 84:2999-3012

Stocker LJ, Underwood AJ (1991) The relationship between the presence of neighbours and rates of sexual and asexual reproduction in a colonial invertebrate. J Exp Mar Biol Ecol 149:191-205

Sultan SE, Stearns SC (2005) Environmentally contingent variation: phenotypic plasticity and norms of reaction. In: Hallgrímsson B, Hall BK (eds) Variation: a central concept in biology. Elsevier Academic Press, Burlington, MA, p 303-332

Tanner JE (1997) Interspecific competition reduces fitness in scleractinian corals. J Exp Mar Biol Ecol 214:19-34

Trussell GC (1996) Phenotypic plasticity in an intertidal snail: the role of a common crab predator. Evolution 50:448-454

Valladares F, Niinemets Ü (2008) Shade tolerance, a key plant feature of complex nature and consequences. Annu Rev Ecol Evol Syst 39:237-257

van Kleunen M, Fischer M, Schmid B (2005) Three generations under low versus high neighborhood density affect the life history of a clonal plant through differential selection and genetic drift. Oikos 108:573-581

van Noordwijk AJ, de Jong G (1986) Acquisition and allocation of resources: their influence on variation in life history tactics. Am Nat 128:137-142

Vermeij MJA, Sandin SA (2008) Density-dependent settlement and mortality structure the earliest life phases of a coral population. Ecology 89:1994-2004

Ye XH, Yu FH, Dong M (2006) A trade-off between guerrilla and phalanx growth forms in Leymus secalinus under different nutrient supplies. Ann Bot 98:187-191

Submitted: August 17, 2009; Accepted: August 3, 2010

Proofs received from author(s): September 15, 2010
Editorial responsibility: Roger Hughes,

Bangor, UK 